\title{
Banana Peel for Acetylsalicylic Acid Retention
}

\author{
Araceli Veronica F. N. Ribeiro ${ }^{1}$, André Romero da Silva ${ }^{2}$, Tiago Pereira da Cunha ${ }^{1}$, \\ Rowenna Tonani L. dos Santos ${ }^{1}$, Jairo Pinto de Oliveira ${ }^{3}$, Evaldo Vitor Pereira ${ }^{3}$, \\ Marcus Vinicius V. J. Licinio ${ }^{3}$, Madson de Godoi Pereira4, Arnaud Victor dos Santos4, \\ Joselito Nardy Ribeiro ${ }^{3 *}$
}

${ }^{1}$ Instituto Federal do Espirito Santo, Campus de Vila Velha, Brazil

${ }^{2}$ Instituto Federal do Espírito Santo, Campus de Aracruz, Brazil

${ }^{3}$ Centro de Ciências da Saúde, Universidade Federal do Espírito Santo, Vitória, Brazil

${ }^{4}$ Departamento de Ciências Exatas e da Terra, Universidade do Estado da Bahia, Salvador, Brazil

Email: *rinajokrauser@gmail.com

How to cite this paper: Ribeiro, A.V.F.N., da Silva, A.R., da Cunha, T.P., dos Santos, R.T.L., de Oliveira, J.P., Pereira, E.V., Licinio, M.V.V.J., de Godoi Pereira, M., dos Santos, A.V. and Ribeiro, J.N. (2016) Banana Peel for Acetylsalicylic Acid Retention. Journal of Environmental Protection, 7, 1850-1859.

http://dx.doi.org/10.4236/jep.2016.712147

Received: September 21, 2016

Accepted: November 20, 2016

Published: November 23, 2016

Copyright $\odot 2016$ by authors and Scientific Research Publishing Inc. This work is licensed under the Creative Commons Attribution International License (CC BY 4.0).

http://creativecommons.org/licenses/by/4.0/

\begin{abstract}
A method for adsorption involving banana peel (BP) was studied to remove the pollutant acetylsalicylic acid (ASA) in aqueous medium. The results show that bioadsorbent has satisfactory maximum adsorption capacity $(2.29 \mathrm{mg} / \mathrm{g})$ for removing this analgesic and anti-inflammatory drug in aqueous solution ( $\mathrm{pH} 7.0)$ using the Langmuir mathematical model. The tested concentrations of this pollutant were higher than the levels commonly found in the aquatic environment. This and other results suggest the BP as an alternative to ASA removal in water contaminated with pharmaceuticals pollutants.
\end{abstract}

\section{Keywords}

Adsorption, Banana Peel, Acetylsalicylic Acid

\section{Introduction}

These pharmaceuticals pollutants are consistently detected in different aquatic environmental samples [1] [2]. The concentrations are usually detected in the order of $\mu \mathrm{g} \cdot \mathrm{L}^{-1}$ and $\mathrm{ng} \cdot \mathrm{L}^{-1}$ [3]. The main sources of contamination are the hospitals [4] and domestic sewage effluents [1]. These drugs and their metabolites may contaminate groundwater, rivers, lakes, and wastewater treatment plants [5] [6]. Montagner and Jardim [7] detected the presence of drugs pollutants in the Atibaia River, Sao Paulo State, Brazil. Among the pharmaceuticals investigated were detected acetylsalicylic acid, acetaminophen, diclofenac and others. The presence of these residues in the environment induces undesirable biological responses in various types of organisms and may 
be dangerous to human health [8]. Therefore, the development of efficient and economical techniques to remove these pollutants pharmaceuticals in the aqueous medium is very important [9]. Among the techniques studied, the adsorption, using natural adsorbents, is one of the most important. The chemical and physical adsorption by natural adsorbents stands out as an efficient and economical alternative for removing pharmaceuticals and other pollutants present in aqueous medium [9] [10] [11] [12]. Among these adsorbents include sugar cane bagasse for removal of textile dyes [10], paracetamol [11] and tetracycline [13], green coconut mesocarp for removal of tetracycline and paracetamol [9], vermicompost for removal of metallic ions, synthetic dyes [14] and paracetamol [15], vegetable sponge for removal of paracetamol [11], goethite for the removal of tetracycline [8] and finally banana peel for removal of phenol [16] and metals [17]. In this work we evaluated the banana peel (BP) for the removal of acetylsalicylic acid (ASA) in aqueous medium. Furthermore, this study aimed to provide a new alternative for the reuse of banana peel, which is abundant in the Brazil.

\section{Material and Methods}

\subsection{Materials}

The bioadsorbent banana peel (BP) was obtained from the banana silver fruit in fairs fruit of Vitoria city, Espírito Santo State, Brazil. The banana silver is the most commonly eaten variety in Brazil. The reactants of analytical degree and deionised water $\left(18.2 \mathrm{M} \Omega \cdot \mathrm{cm}^{-1}\right)$ were used to prepare all of the solutions. Acetylsalicylic acid (ASA) was obtained from Sigma-Aldrich Company (St Louis, MO, USA), hydrochloric acid was purchased from Vetec (Duque de Caxias-RJ, Brazil) and sodium hydroxide from Dinâmica (Diadema-SP, Brazil). The following equipment was used: an analytical balance (Shimadzu AY 220 model), UV/Vis spectrophotometer (Biospectro SP-220 model), infrared (Perkin-Elmer Spectrum-100 model), $\mathrm{pH}$ meter (PHTEK), magnetic stirrer (Nova Ética and Biomixer), laboratory oven (Quimis Q-317 B model), industrial blender (FAET), ultrasonic device (Ultracleaner 1400), scanning electron microscope (SHIMADZU, SSX 550 model), sputter coater (SHIMADZU, IC-50 Ion Coarter model), specific particle size sieves (Granutest), peristaltic pump (Instrutherm, BP 1000), Microtrac (Model Zetratac NPA152).

\subsection{Methods}

\subsubsection{Adsorbent Preparation and Physical Chemistry Analysis}

The adsorbent preparations and physical chemistry analysis of scanning electron microscopy and spectroscopy infrared were performed as previously described by our laboratory in [13]. The BP was washed with hydrochloric acid $0.2 \mathrm{M}$, water ( $\mathrm{pH} 7.0)$ and then dried in a laboratory oven $\left(60^{\circ} \mathrm{C}\right)$ for $15 \mathrm{hrs}$. In the next step, the BP was triturated in an industrial blender with posterior sieving to obtain particle sizes between $1.19 \mathrm{~mm}$ and $4.76 \mathrm{~mm}$. In the scanning electron microscopy the BP particles samples were covered with a thin layer of gold using the sputter coater, and then analyzed using the scanning electron microscope. An electron beam of $10 \mathrm{kV}$ was used, which allowed 
for obtaining micrographs of the physical structure of the BP particles surface. Finally in the spectroscopy infrared analysis the organic functional groups were characterized by Fourier transform IR spectroscopy using $\mathrm{KBr}$ discs to prepare the $\mathrm{BP}$ samples. The spectral range varied from 4000 to $500 \mathrm{~cm}^{-1}$.

\subsubsection{Zeta Potential}

The zeta potential of the particulate material was measured using a particle size analyzer from Microtrac Model Zetatrac NPA152. Typically, aqueous suspension ( $2 \mathrm{ml}$ ) of mashed $\mathrm{BP}$, pretreated at different $\mathrm{pH}$, were added to a Teflon cuvette containing a pair of palladium electrodes for measuring the zeta potential which is determined via electrophoretic mobility of the particles at room temperature $\left(25^{\circ} \mathrm{C}\right.$ on average).

\subsubsection{Evaluation of $\mathrm{pH}$}

The solutions containing $250 \mathrm{ml}$ of $100 \mathrm{mg} \cdot \mathrm{l}^{-1}$ ASA and $3.0 \mathrm{~g}$ of triturated BP were magnetically stirred ( $800 \mathrm{rpm}$ at 10 minutes) at different $\mathrm{pH}$ values (from 3.0 to 10.0). After vacuum filtration, the supernatants were analyzed in an UV/Vis spectrophotometer at maximum absorbance of ASA $(275 \mathrm{~nm})$.

\subsubsection{Evaluation of Stir Time}

At this stage we evaluated the influence of contact time between ASA and BP in the adsorptive process. Therefore, solutions containing $250 \mathrm{ml}$ of $100 \mathrm{mg} \cdot \mathrm{l}^{-1}$ ASA ( $\mathrm{pH} 7.0$ ) were magnetically stirred $(800 \mathrm{rpm}$ ) at different times (from 0 to 25 minutes) in contact with $3.0 \mathrm{~g}$ of triturated BP. After vacuum filtration, the supernatants were analyzed in an UV/Vis spectrophotometer at maximum absorbance of ASA $(275 \mathrm{~nm})$.

\subsubsection{Evaluation of Mass}

The solutions containing $250 \mathrm{ml}$ of $100 \mathrm{mg} \cdot \mathrm{l}^{-1}$ ASA (pH 7.0) were magnetically stirred (800 rpm at 15 minutes) at different mass values of triturated BP (from 0.5 to $5.0 \mathrm{~g}$ ). After vacuum filtration, the supernatants were analyzed in an UV/Vis spectrophotometer at maximum absorbance of ASA $(275 \mathrm{~nm})$.

\subsubsection{Obtaining the Maximum Adsorption Capacity}

At this stage we evaluated the maximum adsorption capacity (MAC) of BP for ASA at $25^{\circ} \mathrm{C} \pm 1{ }^{\circ} \mathrm{C}$. Adsorption isotherms were built for estimating the MAC value. This value represents the amount of ASA which can be adsorbed by $1 \mathrm{~g}$ of triturated BP. For this purpose, $100 \mathrm{ml}$ of ASA solutions at different concentrations (from 10 to $60 \mathrm{mg} \cdot \mathrm{l}^{-1}$ ) were stirred in the conditions previously established: $\mathrm{pH}$ 7.0, $3.0 \mathrm{~g}$ of triturated BP and 15 minutes for stir time. The data obtained in this step were important for obtaining the adsorption isotherm using the mathematical model described by Equation (1) [18]:

$$
q=a \times b \times C e q \times(1+a \times C e q)^{-1}
$$

where $q$ represents the quantity of ASA (mg) adsorbed in triturated BP (g) (mg.g $\left.\mathrm{g}^{-1}\right), a$ represents the constant related to adsorption energy $\left(1 \cdot \mathrm{mg}^{-1}\right), b$ is the maximum ASA adsorption capacity of the BP ( $\left.\mathrm{mg} \cdot \mathrm{g}^{-1}\right)$, and $\mathrm{Ceq}$ is the equilibrium ASA concentration $\left(\mathrm{mg} \cdot \mathrm{l}^{-1}\right)$. The linearizing of this equation permits the obtaining of Equation (2): 


$$
C e q / q=(a \times b)^{-1}+(b)^{-1} \times C e q
$$

which permits calculation of MAC value.

\section{Results and Discussion}

\subsection{Scanning Electron Microscopy and Spectroscopy Infrared Analysis}

The scanning electron microscopy revealed that the BP adsorbent an irregular morphology characterized by the presence of concavities of different sizes (Figure 1).

Furthermore, the data obtained through the spectroscopy infrared analysis (Figure 2)

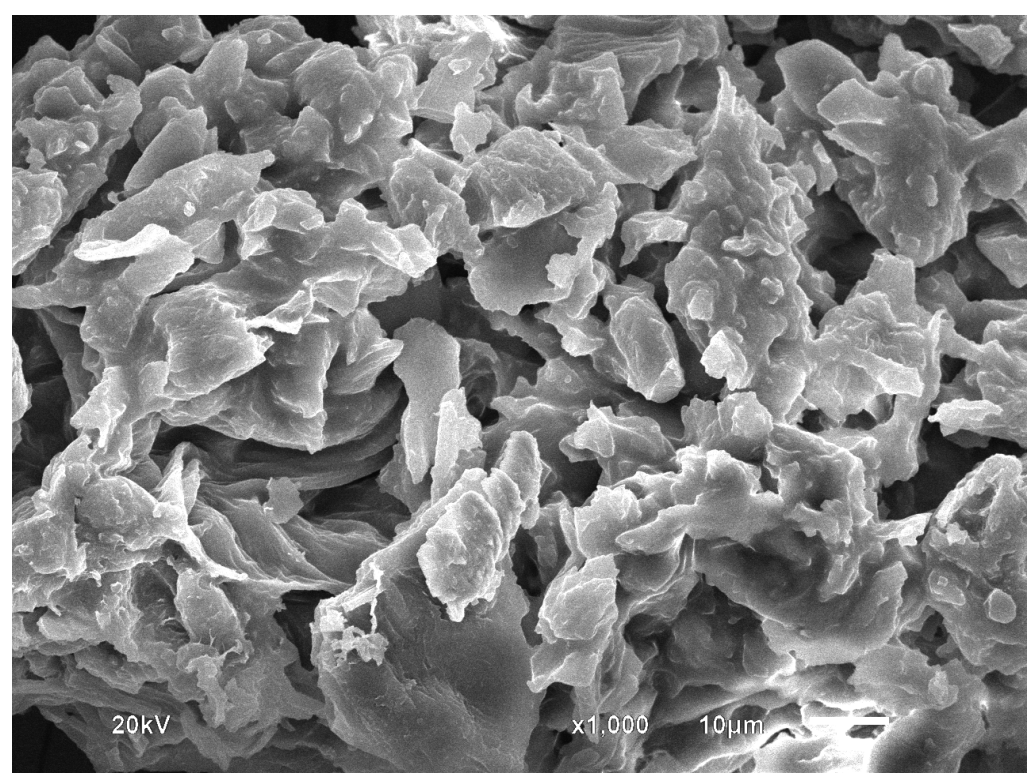

Figure 1. Scanning electron microscopy of banana peel with magnifications of 1000x.

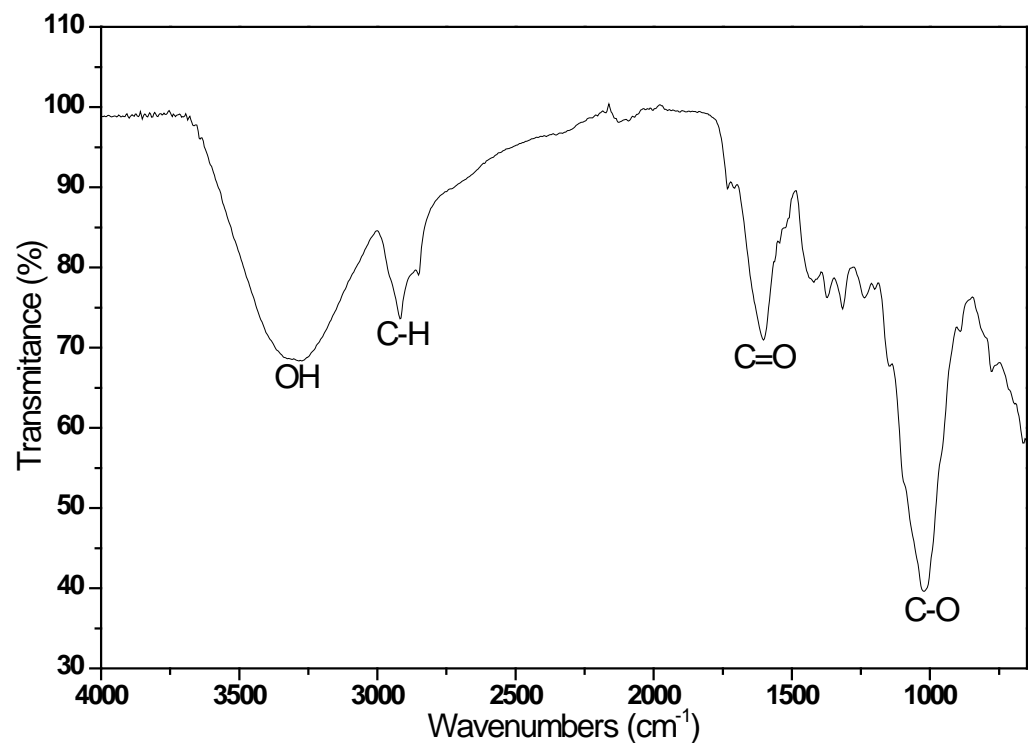

Figure 2. Spectroscopy infrared analysis of banana peel. 
of $\mathrm{BP}$ revealed the presence of important chemicals groups, for interaction with ASA structure (Figure 3). The following groups were found on BP: O-H group (3500 - 3400 $\mathrm{cm}^{-1}$ ) probably from the alcohols, $\mathrm{C}-\mathrm{H} \mathrm{sp}{ }^{3}$ carbon in approximately $2920 \mathrm{~cm}^{-1}, \mathrm{C}=\mathrm{O}$ in approximately at $1666 \mathrm{~cm}^{-1}$ and, finally the presence of the band at $1000 \mathrm{~cm}^{-1}$ may indicate the presence of the carbon group C-O [19]. The presence of these chemical groups is mainly due to the occurrence of biomolecules such as cellulose, hemicellulose and lignin [9].

Finally, the superficial morphology and presence these chemical groups in BP suggests that this natural adsorbent has important characteristics for interaction with ASA.

\subsection{Zeta Potential}

The zeta potential analysis of triturated $\mathrm{BP}$, present in aqueous suspension $(2 \mathrm{ml})$ at different $\mathrm{pH}$, revealed that surface charge of this natural adsorbent becomes more negative in increase of $\mathrm{pH}$ (Figure 4). Probably this increase of negative charge occurred because of deprotonation of $\mathrm{O}-\mathrm{H},-\mathrm{COOH}$, and other chemical groups from various biomolecules of BP constituents. Duran and Flores [20] observed this same behavior when performing the zeta potential analysis of vermicompost natural adsorbent.

\subsection{Evaluation of $\mathrm{pH}$}

The adsorption tests at different $\mathrm{pH}$ of ASA solutions showed that adsorption percentage<smiles>CC(=O)Oc1ccccc1C(=O)O</smiles>

Figure 3. Acetylsalicylic Acid structure.

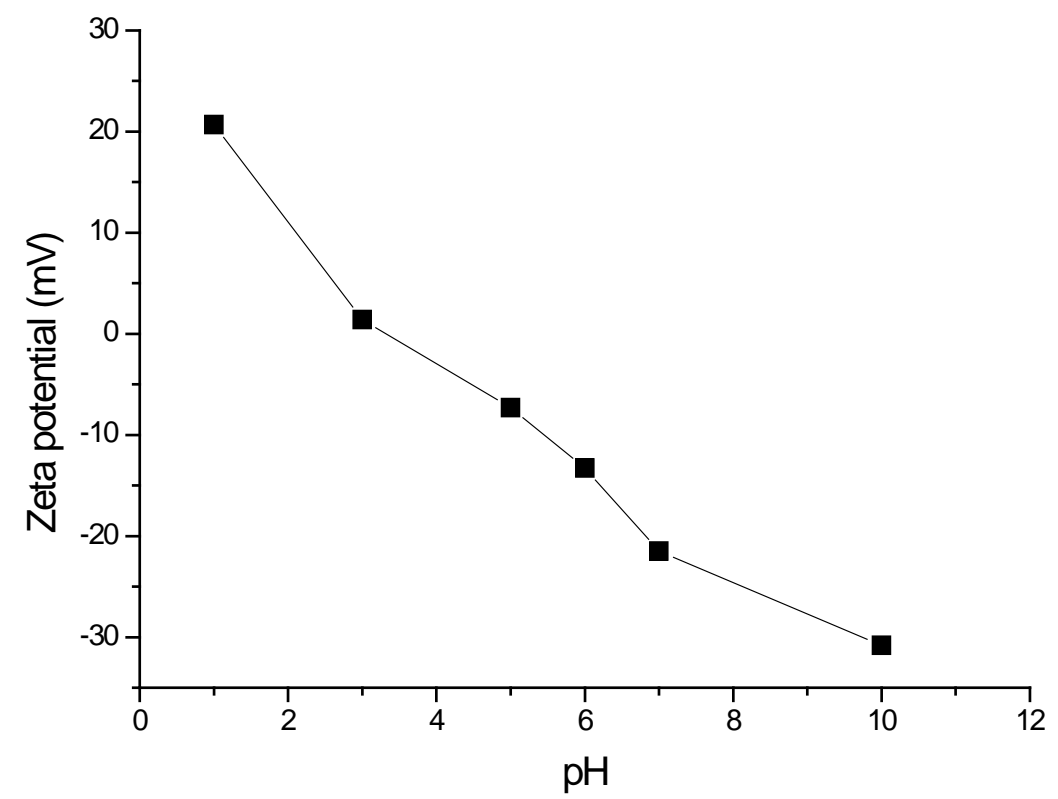

Figure 4. Zeta potential analysis of triturated $\mathrm{BP}$ at different $\mathrm{pH}$. 
of ASA decreases by increasing the $\mathrm{pH}$ of the aqueous solution (Figure 5). Possibly, this result is due to the increase of negative charges of the adsorbate $\left(\mathrm{pk}_{\mathrm{a}} 3.50\right)$ (Figure 6) and adsorbent at higher $\mathrm{pH}$, causing repulsion between ASA and BP. This result is in agreement with Figure 5 that showed an increase in the negative surface charge BP at higher $\mathrm{pH}$ than 3.0. Duran and Flores [20] observed that vermicompost adsorbent acquires a negative charge at high $\mathrm{pH}$ which makes an efficient adsorbent for the removal of the positive lead $\left(\mathrm{Pb}^{2+}\right)$ adsorbate in an aqueous medium. Despite the $\mathrm{pH} 3.0$ is considered to be more efficient in removing the ASA from aqueous medium, it was decided to use the $\mathrm{pH} 7.0$ due to its use in water treatment plants in Brazil.

\subsection{Evaluation of Stir Time}

Figure 7 showed that the satisfactory percentage adsorption of the drug occurred at 15 minutes of stirring and after this time observed a decrease in the drug adsorption. Probably, this decrease is related to the desorption of ASA from the BP, due to the system's constant stirring and weak interactions between the drug and the banana peel [10].

\subsection{Evaluation of Mass}

Figure 8 shows the influence of the BP adsorbent mass on percentage of ASA adsorption. The better retention of the drug occurred with use of $1.5 \mathrm{~g}$ of adsorbent. The

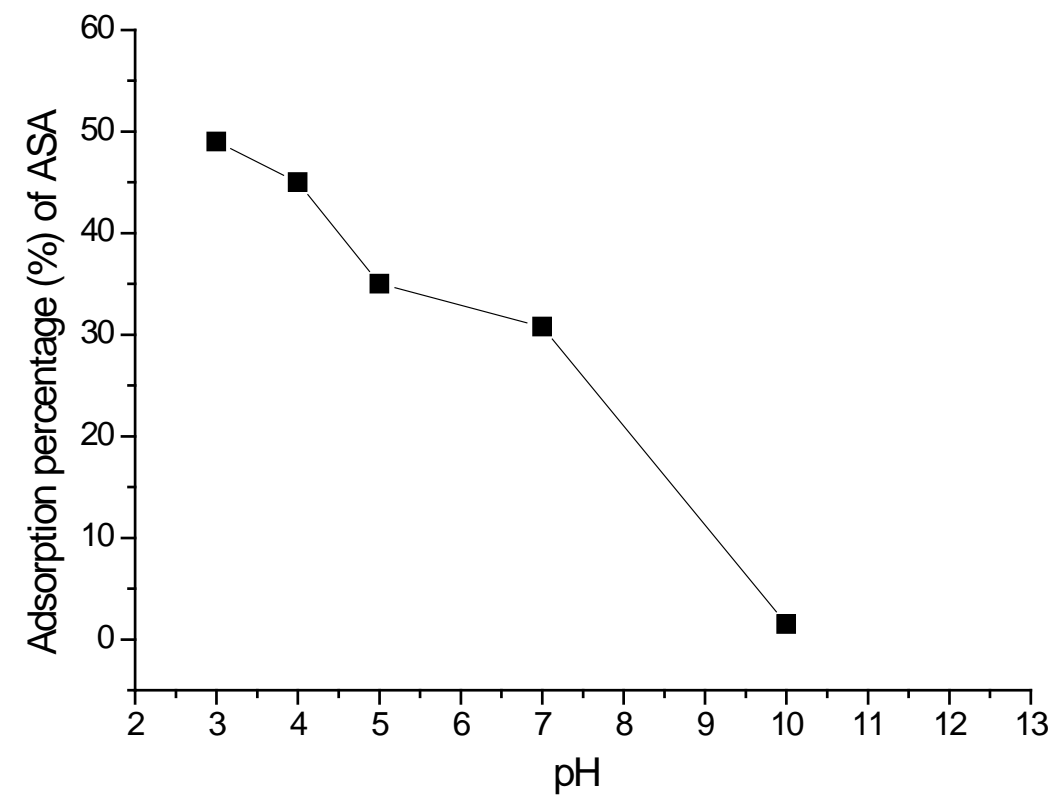

Figure 5. Influence of $\mathrm{pH}$ in the percentage adsorption of ASA by BP.

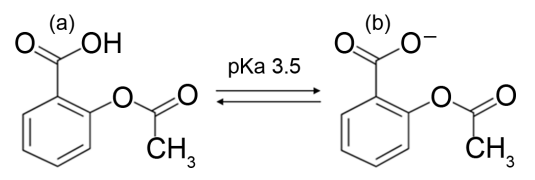

Figure 6. Protonated (a) and unprotonated (b) ASA structure. 


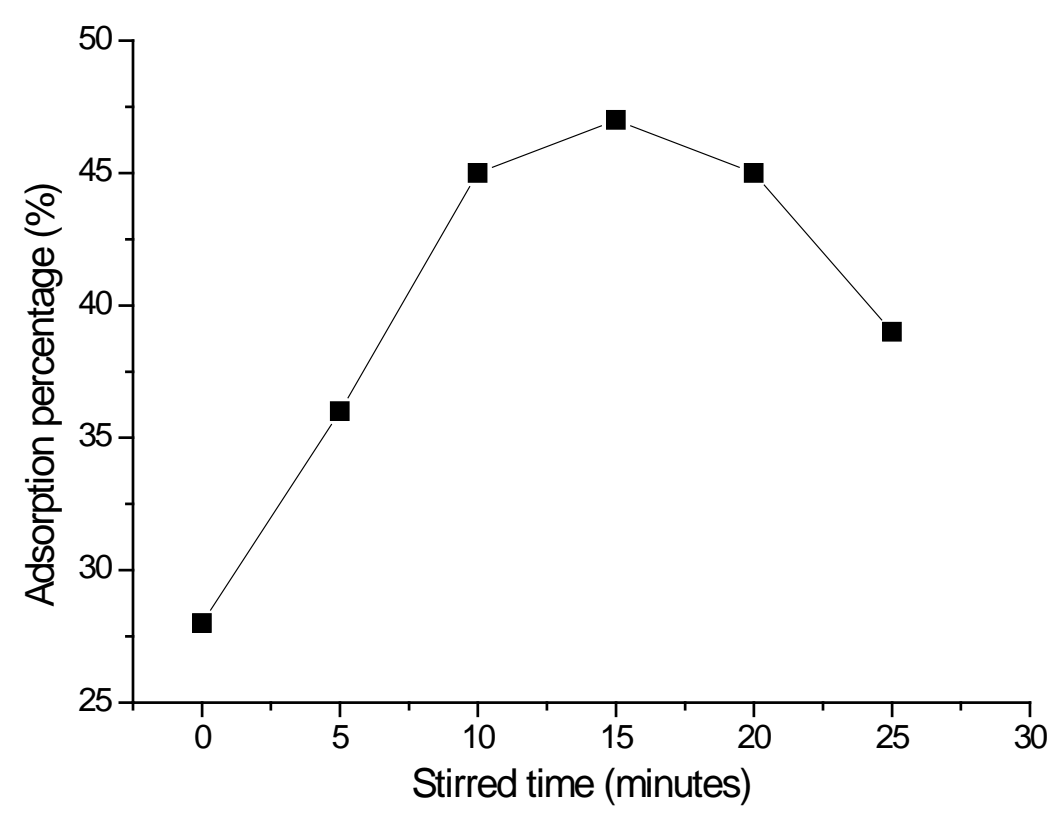

Figure 7. Influence of the stir time in the percentage of ASA adsorption by BP.

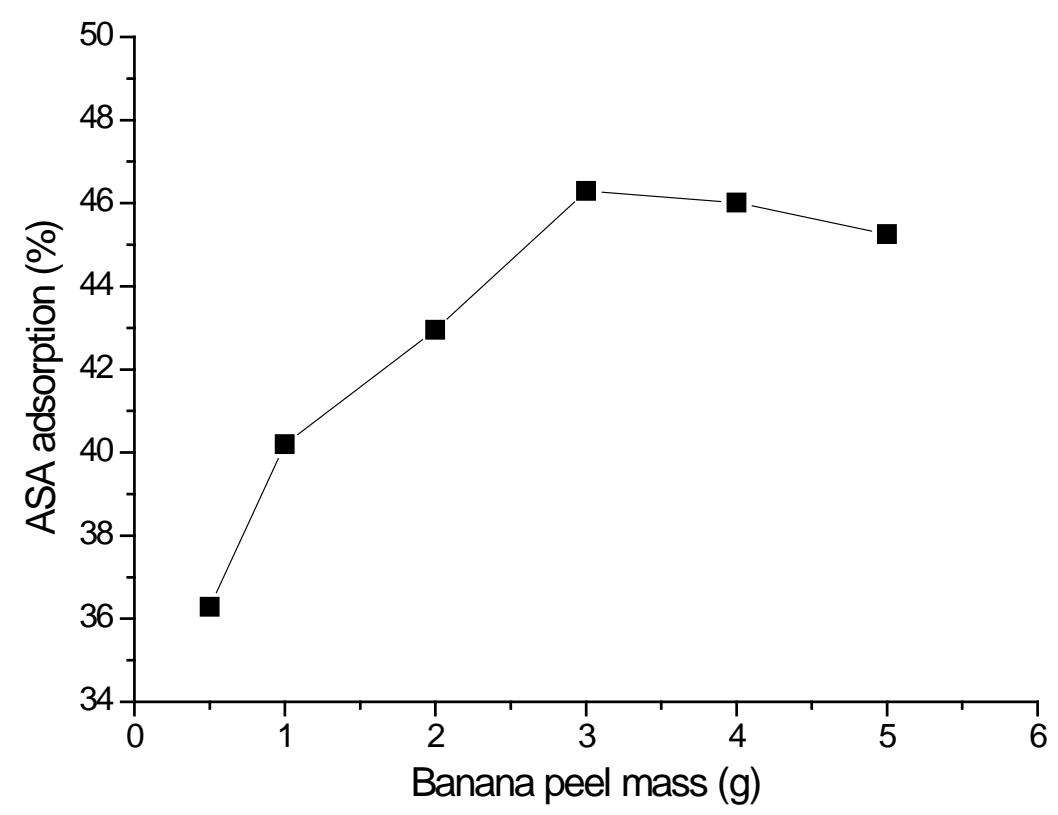

Figure 8. Influence of the banana peel mass in the percentage of ASA adsorption.

quantity of adsorbent to be used is very important; not only to have a good retention of the pollutant, but also to project the area required to stock the adsorbent resulting from the treatment [10].

\subsection{Maximum Adsorption Capacity (MAC)}

To determine the MAC of BP adsorbent to ASA, adsorption isotherm (Figure 9) was obtained from different ASA concentrations. Then the isotherm was linearized (Figure 10) according to the Langmuir Mathematical Model [18]. The MAC value $2.29 \mathrm{mg} / \mathrm{g}$ 


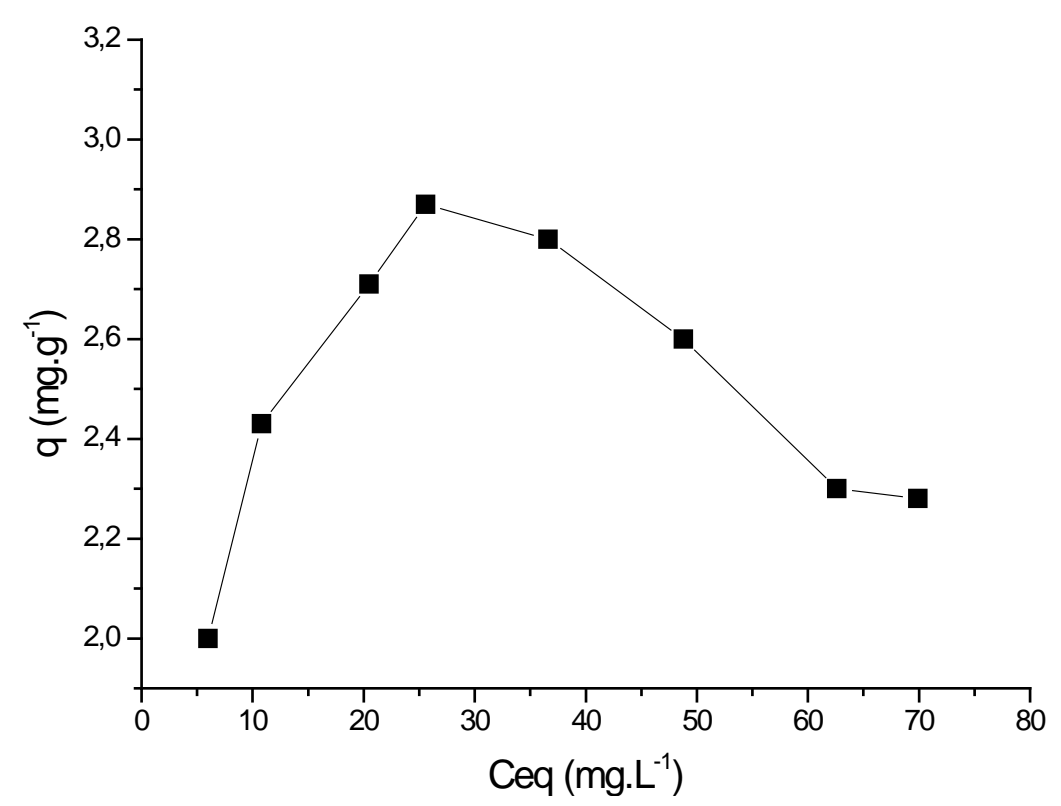

Figure 9. Isotherm adsorption.

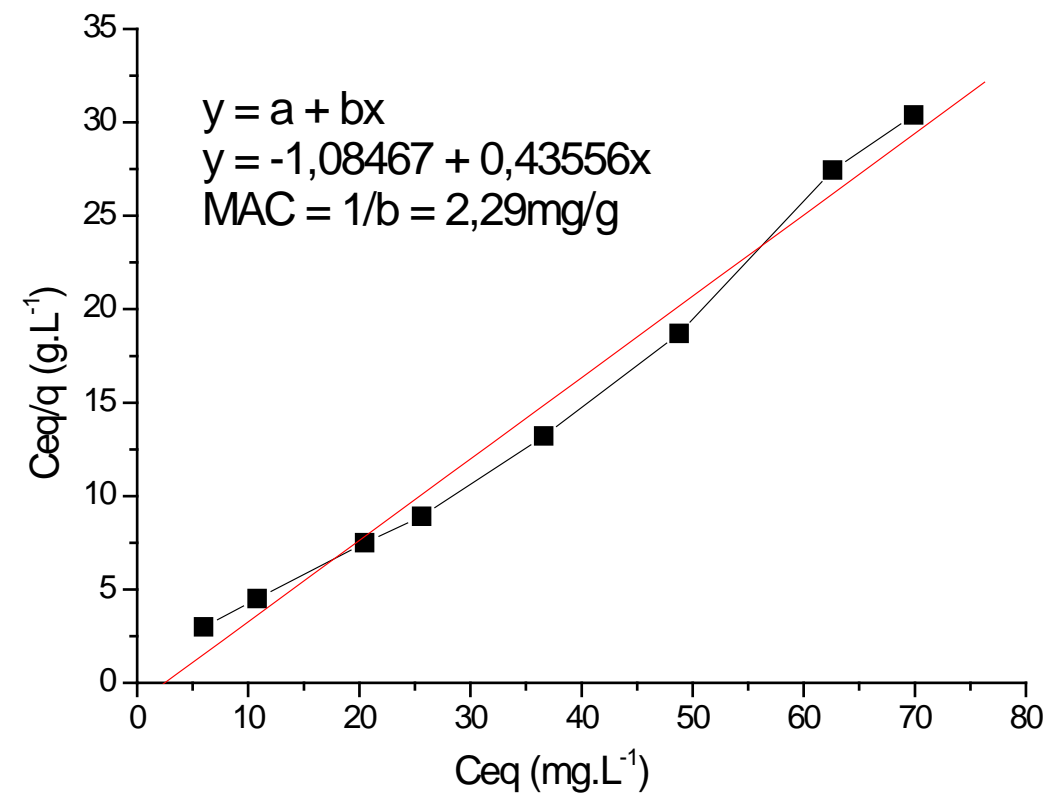

Figure 10. Isotherm linearized adsorption.

obtained for ASA adsorption by BP can be considered satisfactory, because drugs are commonly found in aquatic environmental at $\mu \mathrm{g} / \mathrm{L}$ or $\mathrm{ng} / \mathrm{L}$ [3] [4]. In previous studies [9] and [13] also found satisfactory MAC values for paracetamol and tetracycline utilizing the natural adsorbents green coconut mesocarp and sugar cane bagasse respectively. Ribeiro et al. [11] found interesting results for the removal of paracetamol using sugar cane bagasse and vegetable sponge as natural adsorbents. Finally was verified that several authors studied diverse types of natural adsorbents for retention of several chemical pollutants from water in stirring system and columns. These studies obtained 
satisfactory MAC values [21].

\section{Conclusion}

The results suggest that BP has characteristics that qualify it as a possible natural adsorbent for water treatment containing ASA pollutant. This material showed satisfactory maximum adsorption capacity. Finally, the results encourage more detailed studies, including the retention of other pollutants and economic viability.

\section{Acknowledgements}

The authors would like to thank the Federal Institute of Espírito Santo (Vila Velha, ES, Brazil) by financial support, and Laboratory of Cellular Ultra structure Carlos Alberto Redins of Federal University of Espírito Santo (Vitória, ES, Brazil) for the use of scanning electron microscopes.

\section{References}

[1] Ziylan, A. and Ince, N.H. (2011) The Occurrence and Fate of Anti-Inflammatory and Analgesic Pharmaceuticals in Sewage and Fresh Water: Treatability by Conventional and NonConventional Process Comparative Study of MR Imaging Profile of Titanium Pedicle Screws. Journal of Hazardous Materials, 187, 24-36. https:/doi.org/10.1016/j.jhazmat.2011.01.057

[2] Daneshvar, A., Aboulfadl, K., Viglino, L., Broséus, R., Sauvé, S., Madoux-Humery, A.S., Weyhenmeyer, G.A. and Prévost, M. (2012) Evaluating Pharmaceuticals and Caffeine as Indicators of Fecal Contamination in Drinking Water Sources of the Greater Montreal Region. Chemosphere, 88, 131-139. https:/doi.org/10.1016/j.chemosphere.2012.03.016

[3] Hilton, M.J. and Thomas, K.V. (2003) Determination of Selected Human Pharmaceutical Compounds in Effluent and Surface Water Samples by High-Performance Liquid Chromatography-Electrospray Tandem Mass Spectrometry. Journal of Chromatography A, 1015, 129-141. https:/doi.org/10.1016/S0021-9673(03)01213-5

[4] Azuma, T., Arima, N., Tsukada, A., Hirami, S., Matsuoka, R., Moriwake, R., Ishiuchi, H., Inoyama, T., Teranishi, Y., Yamaoka, M., Mino, Y., Hayashi, T., Fugita, Y. and Masada, M. (2016) Detection of Pharmaceuticals and Phytochemicals Together with Their Metabolites in Hospital Effluents in Japan, and Their Contribution to Sewage Treatment Plant Influents. Science of the Total Environmental, 548-549, 189-197.

https:/doi.org/10.1016/j.scitotenv.2015.12.157

[5] Fatta-Kassinos, D., Meric, S. and Nikolaou, A. (2011) Pharmaceutical Residues in Environmental Waters and Wastewater: Current State of Knowledge and Future Research. Analytical and Bioanalytical Chemistry, 399, 251-275. https:/doi.org/10.1007/s00216-010-4300-9

[6] Tewari, S., Jindal, R., Kho, Y.L., Eo, S. and Choi, K. (2013) Major Pharmaceutical Residues in Wastewater Treatment Plants and Receiving Waters in Bangkok, Thailand, and Associated Ecological Risks. Chemosphere, 91, 697-704.

https:/doi.org/10.1016/j.chemosphere.2012.12.042

[7] Montagner, C.C. and Jardim, W.F. (2011) Spatial and Seasonal Variations of Pharmaceuticals and Endocrine Disruptors in the Atibaia River, São Paulo State (Brazil). Journal of the Brazilian Chemical Society, 22, 1452-1462.

https:/doi.org/10.1590/S0103-50532011000800008 
[8] Zhao, Y., Geng, J., Wang, X., Gu, X. and Gao, S. (2011) Adsorption of Tetracycline onto Goethite in the Presence of Metal Cations and Humic Substances. Journal of Colloid and Interface Science, 361, 247-251. https:/doi.org/10.1016/j.jcis.2011.05.051

[9] Ribeiro, J.N., Ribeiro, A.V.F.N., Oliveira, J.P., Leao, R.T. and Cunha, T.P. (2016) Green Mesocarp Coconut for Treatment of Water Contaminated with Paracetamol and Tetracycline. International Journal of Scientific Research, 5, 319-323.

[10] Raymundo, A.S., Zanarotto, R., Belisário, M., Pereira, M.G., Ribeiro, J.N. and Ribeiro, A.V.F.N. (2010) Evaluation of Sugar-Cane Bagasse as Bioadsorbent in the Textile Wastewater Treatment Contaminated with Carcinogenic Congo Red Dye. Brazilian Archives of Biology and Technology, 53, 931-938. https:/doi.org/10.1590/S1516-89132010000400023

[11] Ribeiro, A.V.F.N., Belisário, M., Galazzi, R.M., Balthazar, D.C., Pereira, M.G. and Ribeiro, J.N. (2011) Evaluation of Two Bioadsorbents for Removing Paracetamol from Aqueous Media. Electronic Journal of Biotechnology, 14, 1-10.

[12] Pereira, M.G, Neta, L.C.S, Fontes, M.P.F., Nascimento, A., Matos, T.C., Sachdev, R.L., Santos, A.V., Souza, M.O.G., Andrade, M.V., Paulo, M.M., Ribeiro, J.N. and Ribeiro, A.V.F.N. (2014) An Overview of the Environmental Applicability of Vermicompost: From Wastewater Treatment to the Development of Sensitive Analytical Methods. The Scientific World Journal, 2014, Article ID: 917348. https:/doi.org/10.1155/2014/917348

[13] Ribeiro, A.V.F.N., Cosmo, P.C., Pereira, M.G., Dalfior, B.M., Gonçalves, G.S., Licinio, M.V.V.J., Endringer, D.C., Oliveira, J.P. and Ribeiro, J.N. (2014) Use of Sugarcane Bagasse for Adsorption of Tetracycline in Aqueous Medium. Indian Journal of Applied Research, 4, 10-14. https:/doi.org/10.15373/2249555X/JAN2014/4

[14] Pereira, M.G., Matos, T.C., Santos, N.C.V., Santos, A.M., Neta, L.C.S., Ribeiro, J.N., Ribeiro, A.V.F.N., Oliveira, J.P., Guimarães, M.C.C. and Licinio, M.V.V.J. (2015) Evaluation of Vermicomposts for Decontaminating Aqueous Media Containing Metallic Ions and Synthetic Dyes. In: Bates, L., Org., Humic Substances and Natural Organic Matter, Nova Science Publishers, Hauppauge, Vol. 1, 83-114.

[15] Ribeiro, J.N., Ribeiro, A.V.F.N., Licinio, M.V.V.J., Pereira, M.G., Dalfior, B.M., Oliveira, J.P., Cosmo, P.C., Galazzi, R.M., Pereira, E.V. and Guimarães, M.C.C. (2014) Studies on the Removal of Paracetamol from Aqueous Medium Using Vermicompost. Analytica, 12, 64-68.

[16] Ali, A. and Saeed, K. (2016) Phenol Removal from Aqueous Medium Using Chemically Modified Banana Peel Powder as Low-Cost Adsorbent. Desalination and Water Treatment, 57, 11242-11254. https:/doi.org/10.1080/19443994.2015.1041057

[17] Salim, R.M., Chowdhury, A.J.K., Rayathulhan, R., Yunus, K. and Sakar, M.Z.I. (2016) Biosorption of $\mathrm{Pb}$ and $\mathrm{Cu}$ from Aqueous Solution Using Banana Peel Powder. Desalination and Water Treatment, 57, 303-314.

[18] Pereira, M.M., Korn, M., Santos, B.B. and Ramos, M.G. (2009) Vermicompost for Tinted Cationic Dyes Retention. Water Air and Soil Pollution, 200, 227-235. https:/doi.org/10.1007/s11270-008-9906-6

[19] Silverstein, R.M., Basller, G.C. and Morril, T.C. (1979) Spectrotometry Identification of Organic Compouds. 3rd Edition, John Willey \& Sons, Hoboken.

[20] Duran, A.C. and Flores, I. (2009) Evaluation of Lead(II) Immobilization by a Vermicompost Using Adsorption Isotherms and IR Spectroscopy. Bioresource Technology, 100, 16911694. https:/doi.org/10.1016/j.biortech.2008.09.013

[21] Belisario, M., Borges, P.S., Galazzi, R.M., Del Piero, P.B., Ribeiro, A.V.F.N. and Ribeiro, J.N. (2009) The Employment of Natural Waste at Treatment of Effluents Contaminated with Polluting Medicines. InterSciencePlace, 2, 1-13. 
Submit or recommend next manuscript to SCIRP and we will provide best service for you:

Accepting pre-submission inquiries through Email, Facebook, LinkedIn, Twitter, etc. A wide selection of journals (inclusive of 9 subjects, more than 200 journals)

Providing 24-hour high-quality service

User-friendly online submission system

Fair and swift peer-review system

Efficient typesetting and proofreading procedure

Display of the result of downloads and visits, as well as the number of cited articles

Maximum dissemination of your research work

Submit your manuscript at: http://papersubmission.scirp.org/

Or contact jep@scirp.org 